\title{
Caracterização imunoistoquímica de neoplasias de bexigas associadas à hematúria enzoótica bovina
}

\section{Immunohistochemical characterization of neoplasms of the urinary bladder associated with bovine enzootic hematuria}

\author{
Maria Aparecida da Silva ${ }^{1}$; Julio Lopes Sequeira²; \\ Ana Paula Madureira ${ }^{3}$; Louisiane Carvalho Nunes ${ }^{4 *}$
}

\begin{abstract}
Resumo
A hematúria enzoótica bovina é caracterizada pelo desenvolvimento de lesões hemangiomatosas relacionadas a diversos tipos de processos neoplásicos de origem epitelial e mesenquimal. $\mathrm{O}$ uso de biomarcadores pode auxiliar na classificação tumoral. Objetivou-se com este trabalho determinar a histogênese das lesões neoplásicas encontradas em bexigas, de animais da microrregião do Caparaó, ES com hematúria enzoótica bovina. Para isto foi realizada a imunoistoquímica com os anticorpos primários: anti-vimentina, anti-citoqueratina, anti-CD31 e anti-uroplaquina. As neoplasias encontradas foram carcinoma urotelial, carcinoma in situ, adenocarcinoma, hemangioma, mixoma e hemangiossarcoma. As marcações da citoqueratina em neoplasias epiteliais e da vimentina em neoplasias mesenquimais foram significativas $(\mathrm{p}<0,05)$. CD31 mostrou positividade em todos os vasos de todas as amostras, no entanto, a marcação foi significativa $(\mathrm{p}<0,05)$ nas células endoteliais tumorais das neoplasias mesenquimais de origem vascular, como hemangiomas e hemangiossarcomas. A marcação da uroplaquina III foi diferente nos diversos tipos neoplásicos e não demonstrou diferença significativa $(p>0,05)$. Em relação ao tipo de marcação no urotélio, observou-se que a maioria das neoplasias mostrou marcação atípica, entretanto, nos hemangiossarcomas não houve marcação do urotélio em nenhuma das amostras. A análise estatística de Spearman revelou correlação positiva $\left(r_{s}=0,63, p=0,05\right)$ entre vimentina e CD31 e entre citoqueratina e uroplaquina $\left(r_{s}=0,61, p=0,05\right)$. Concluiu-se que os biomarcadores anti-citoqueratina, anti-vimentina e anti-CD31 são importantes para o diagnóstico das neoplasias epiteliais, mesenquimais e vasculares, respectivamente. É possível utilizar em associação vimentina e CD31 em neoplasias mesenquimais vasculares e citoqueratina e uroplaquina em neoplasias epiteliais. A uroplaquina demonstrou-se um marcador efetivo não somente para o diagnóstico tumoral, mas também para a avaliação da integridade urotelial.
\end{abstract}

Palavras-chave: Citoqueratina, vimentina, CD31, uroplaquina III, hematúria enzoótica bovina

\begin{abstract}
Bovine enzootic hematuria is characterized by the development of hemangiomatous lesions from several types of neoplastic processes, from epithelial and mesenchymal origin. In this research the histogenesis
\end{abstract}

${ }^{1}$ Discente de Doutorado do Programa de Pós-graduação em Ciência Animal. Universidade Estadual do Norte Fluminense Darcy Ribeiro. UENF, Campos dos Goytacazes, Rio de Janeiro, RJ. E-mail: mv_mariaaparecida@yahoo.com.br

${ }^{2}$ Prof. do Dept ${ }^{\circ}$ de Clínica Veterinária. Faculdade de Medicina Veterinária ē Zootecnia da Universidade Estadual Paulista “Julio de Mesquita Filho", UNESP, Botucatu, SP. E-mail: sequeira@fmvz.unesp.br

${ }^{3}$ Prof $^{a}$ do Dept ${ }^{o}$ de Engenharia de Biossistemas. Universidade Federal de São João Del Rei, UFSJ, São João Del Rei, MG. E-mail: ana paulamad@hotmail.com

${ }^{4}$ Prof $^{\mathrm{a}}$ do Dept ${ }^{\mathrm{O}}$ de Medicina Veterinária. Centro de Ciências Agrárias. Universidade Federal do Espírito Santo, UFES, Alegre, ES. E-mail: louisianecn@yahoo.com.br; louisiane.nunes@ufes.br

* Autor para correspondência 
of neoplastic lesions found in bladder of bovines with enzootic hematuria from Caparaó microregion in the state of Espírito Santo, Brazil was determined. To accomplish this objective, immunohistochemical analysis was performed with primary antibodies: anti-vimentin, anti-cytokeratin, anti-CD31 and anti-uroplakin. Neoplasms found included urothelial carcinoma, in situ carcinoma, adenocarcinoma, hemangioma, myxoma e hemangiosarcoma. Immunohistochemical staining of cytokeratin in epithelial neoplasms and vimentin in mesenchymal neoplasms was significant $(p<0.05)$. CD31 was positive in all the vessels of all samples, however, the staining was significant $(\mathrm{p}<0.05)$ in the tumor endothelial cells of the vascular mesenchymal neoplasms, as in hemangiomas and hemangiosarcomas. Uroplakin III staining was uneven in several neoplastic types and showed no significant difference ( $p>0.05)$. Most neoplasms showed an atypical uroplakin staining on urothelium and, in the case of hemangiosarcomas there was no staining of the urothelium at all. The Spearman statistical analysis revealed a positive correlation $(r=0.63, p=0.05)$ between $\mathrm{CD} 31$ and vimentin and between cytokeratin and uroplakin $(\mathrm{rs}=-0.61, \mathrm{p}=0.05)$. It was concluded that biomarkers anti-cytokeratin, anti-vimentin and anti-CD31 are important for the diagnosis of neoplasms epithelial, mesenchymal and vascular mesenchymal, respectively. It is possible to use vimentin and CD31 in association in vascular mesenchymal neoplasms and cytokeratin and uroplakin in epithelial neoplasms. The uroplakin is an effective marker, not only for tumor diagnosis, but also to evaluate the urothelial integrity.

Key words: Cytokeratin, vimentin, CD31, uroplakin III, bovine enzootic hematuria

\section{Introdução}

A ingestão por bovinos, de Pteridium aquilinum, conhecida vulgarmente como samambaia, em uma quantidade inferior a $10 \mathrm{~g} \mathrm{~kg}^{-1} \mathrm{dia}^{-1}$, durante um ou mais anos pode ocasionar uma doença não infecciosa e crônica denominada hematúria enzoótica bovina (HEB) (TOKARNIA; DÖBEREINER; PEIXOTO, 2000). A HEB é caracterizada pelo desenvolvimento de neoplasias na mucosa da bexiga dos bovinos e desencadeia a presença de sangue na urina (RADOSTITIS et al., 2007). O papilomavírus bovino (BPV) associado à intoxicação por samambaia pode estar envolvido na patogênese da doença (CAMPO et al., 1992).

As bexigas dos animais acometidos por HEB podem conter em suas paredes lesões hemangiomatosas relacionadas a diversos tipos de processos neoplásicos de origem epitelial e mesenquimal (TOKARNIA; DÖBEREINER; PEIXOTO, 2000). E um mesmo animal pode apresentar em sua bexiga mais de um tipo de neoplasma com histogênese variada (PEIXOTO et al., 2003; GABRIEL et al., 2009).

Apesar da diversidade tumoral encontrada nas bexigas de animais com HEB não há um esclarecimento histológico acurado das variantes das neoplasias destas bexigas (BORZACCHIELLO et al., 2004), enquanto que em humanos há descrição detalhada de diversas variantes de carcinoma urotelial, por exemplo (MOSTOFI; DAVIS, 1999).

Utilizar a imunoistoquímica, que combina técnicas histológicas, imunológicas e bioquímicas, a fim de detectar antígenos tissulares in situ por meio de anticorpos específicos e moléculas marcadoras, pode estabelecer o diagnóstico preciso das neoplasias e suas origens (RAMOS-VARA, 2005).

Por meio da técnica de imunoistoquímica, os tumores epiteliais como papilomas e carcinoma transicionais são positivos para marcadores biomoleculares como citoqueratina e uroplaquina III (RAMOS-VARA, 2005), e para os tumores de origem mesenquimal, como os vasculares, a vimentina e o CD31 podem ser mais específicos (TORRES-OLIVEIRA et al., 2001; RAMOSVARA, 2005).

As citoqueratinas englobam uma grande gama de proteínas filamentares de tamanho médio que compõem o citoesqueleto das células epiteliais (MOLL et al., 1982). Os anticorpos monoclonais AE1 podem identificar citoqueratinas ácidas (baixo peso molecular $56,5 \mathrm{kDa}$ ), enquanto os anticorpos monoclonais AE3 identificam citoqueratinas básicas 
(alto peso molecular de 65 a $67 \mathrm{kDa}$ ) (SCHLEGEL et al., 1980).

As uroplaquinas são encontradas nas células superficiais do urotélio, principalmente em estágios avançados de diferenciação urotelial e formam um complexo extremamente insolúvel. Foram isoladas da bexiga de bovinos três tipos de uroplaquina de acordo com seus pesos moleculares uroplaquina I (27 kDa), uroplaquina II (15 kDa) e uroplaquina III (47 kDa). No entanto, as uroplaquinas I e II foram encontradas apenas na superfície do urotélio, e a uroplaquina III foi encontrada em todas as camadas do urotélio maduro (WU et al., 1990).

Posteriormente $\mathrm{Yu}$ et al. (1994) constataram na bexiga de bovinos que há duas isoformas para a uroplaquina I, uroplaquina Ia com $27 \mathrm{kDa}$ e uroplaquina $\mathrm{Ib}$ com $28 \mathrm{kDa}$. Os quatro tipos de uroplaquina, Ia, Ib, II e III foram encontradas também no urotélio de bexigas de humanos, macacos, ovinos, suínos, caninos, coelhos, ratos e camundongos (WU et al., 1994).

Nas células de origem mesenquimal como os fibroblastos, células endoteliais, leucócitos e células mioepiteliais a vimentina é o principal filamento intermediário que compõe o citoesqueleto e participa na arquitetura celular, integridade tecidual, adesão, migração e sinalização celular (IVASKA et al., 2007).

A molécula de adesão celular endotelial plaquetária 1 (PECAM-1) também conhecida como CD31 mantêm a integridade endotelial através da adesão célula-célula ou célula-matriz extracelular e auxilia na passagem das células sanguíneas para a luz dos vasos (BEHAR et al., 1996; BLANKENBERG; BARBAUX; TIRET, 2003; LISTI et al., 2004), pode se expressar na superfície de células endoteliais, plaquetas e leucócitos (ELRAYESS; TALMUD, 2005), como macrófagos e histiócitos (AKIBA et al., 2011).

O biomarcador CD31 foi utilizado de forma eficiente em humanos para o diagnóstico de angiossarcomas (POHAR-MARINSEK;
LAMOVEC, 2010) e no diagnóstico de hemangiossarcoma em macaco aranha de cara vermelha (CASAGRANDE et al., 2009).

Devido à existência de muitos casos de HEB, $56,4 \%$ de prevalência na microrregião do Caparaó, sul do estado do Espírito Santo, (SILVA et al., 2009), objetivou-se com este trabalho determinar a histogênese das lesões neoplásicas encontradas em bexigas, bem como, identificar e classificar novas variantes tumorais, de animais da microrregião do Caparaó, ES com hematúria enzoótica bovina, por meio da imunoistoquímica com os biomarcadores anti-vimentina, anti-citoqueratina, anti-CD31 e anti-uroplaquina.

\section{Material e Métodos}

No matadouro frigorífico de Muniz Freire, ES, foram selecionadas 26 bexigas de bovinos machos e fêmeas, oriundos de propriedades localizadas em municípios da microrregião do Caparaó, ES com histórico da presença de Pteridium aquilinum e que apresentavam neoplasias.

As bexigas avaliadas foram previamente seccionadas no sentido caudo-cranial pela face ventral do órgão para constatação da presença de hematúria e/ou de lesões macroscópicas, como hemorragias focais e difusas, lesões hemangiomatosas e papilomatosas. Juntamente com a bexiga inteira foi coletada a urina, em tubos de vidro de $10 \mathrm{~mL}$.

As bexigas foram acondicionadas separadamente em sacos plásticos transparentes, identificadas quanto à procedência, e colocadas junto com os tubos de urina devidamente identificados em caixas isotérmicas com gelo para o transporte ao Hospital Veterinário da UFES. No Setor de Patologia Animal a urina foi centrifugada a $2500 \mathrm{rpm}$ por 10 minutos para classificação em macro ou microhematúria, segundo o método descrito por Falbo et al. (2005).

Para uma melhor triagem das lesões, cada bexiga foi dividida em quatro quadrantes (A, B, C e D), que 
correspondiam às porções cranial (A e B) e caudal (C e D) da bexiga, e coletado um fragmento de cada alteração macroscópica observada. Naqueles quadrantes sem lesões visíveis, foi coletado um fragmento do centro do quadrante aleatoriamente.

As amostras foram submetidas ao processamento histológico de rotina para inclusão em parafina. Em seguida, submetidas à confecção de cortes histológicos de três micrômetros em micrótomo rotativo. Estes cortes foram depositados em lâminas histológicas de vidro com extremidade fosca e corados pelo método Hematoxilina-Eosina (HE) para uma avaliação geral das alterações morfológicas e classificação das lesões de acordo com Oliveira (2009).

A técnica de imunoistoquímica foi realizada somente nos fragmentos que apresentaram lesões neoplásicas ao exame microscópico, com a utilização dos seguintes anticorpos primários: antivimentina (Monoclonal Mouse Antibody to Porcine Vimentin (Clone V9) Diagnostic BioSystems ${ }^{\circledR}$ ), anti-citoqueratina (Mouse Anti-Human Pan Cytokeratin Monoclonal Antibody, Clone AE1/AE3, Biocare Medical ${ }^{\circledR}$ ), anti-CD31(Rabbit Anti-Human CD31 Monoclonal Antibody, Clone SP38, Spring Biosciense $^{\circledR}$ ) e anti-uroplaquina (Mouse AntiHuman Uroplakin III Monoclonal Antibody, Clone AU1, Biocare Medical ${ }^{\circledR}$ ), previamente padronizados no Laboratório de Pesquisa do Serviço de Patologia Veterinária da Universidade Estadual Paulista, Botucatu, SP. Para padronização dos biomarcadores anti-vimentina e anti-uroplaquina foram utilizados cortes de bexiga bovina, anti-citoqueratina cortes de adenocarcinoma de glândula ceruminosa canino e para anti-CD-31 cortes de cordão umbilical humano nas diluições de 1:1000, 1:100, 1:800 e 1:200, respectivamente.

Para a realização da imunoistoquímica, inicialmente as lâminas foram mergulhadas em álcool a $70 \%$ e, depois de secas, imersas em cola líquida a base de organosilano (A3648 - SIGMA, St. Louis, E.U.A.). Cortes histológicos com três micrômetros de espessura foram feitos em micrótomo rotativo e depositados sobre as lâminas com cola. As lâminas com os cortes, em seguida, permaneceram na estufa a $60^{\circ} \mathrm{C}$ por 24 horas para fixação do tecido à lâmina.

O bloqueio da peroxidase endógena foi feito utilizando-se solução de água oxigenada a 10 volumes com metanol (1:9) por 10 minutos. Para a recuperação antigênica do material foi utilizada solução tampão de citrato $10 \mathrm{mM}$, pH 6,04, em Pascal (panela de pressão microprocessada Dako ${ }^{\circledR}$ Denmark A/S) $125{ }^{\circ} \mathrm{C}$ por 30 segundos. O material foi então resfriado por cerca de 20 minutos até atingir a temperatura ambiente. Após este procedimento foi realizada lavagem com Tris (TRIZMA base, D5637 Sigma Chemical ${ }^{\circledR}$ C.O., St. Louis, E.U.A.) pH 7,42. Em seguida foi realizado o bloqueio de proteínas inespecíficas com leite em pó Molico ${ }^{\circledR}$ a 3\% em Tris por uma hora, em seguida foi realizada lavagem com Tris.

A incubação com os anticorpos primários antivimentina, anti-citoqueratina, anti-CD31 e antiuroplaquina foi realizada após a diluição, 1:1000, 1:800,1:200 e 1:100, respectivamente, em solução de albumina sérica bovina a $0,1 \%$ em câmara úmida por 18 horas a $4{ }^{\circ} \mathrm{C}$. Após este procedimento as lâminas foram lavadas com solução de Tris e utilizado o kit NovoLink ${ }^{\mathrm{TM}}$ (Novocastra Laboratories Ltda. RE7140-K) que contém anticorpo secundário e sistema de amplicação por polímeros. Para visualização da reação, os cortes foram tratados com solução de 3,3' diaminobenzidina (Liquid DAB - K3466 Dako ${ }^{\circledR}$ Cytomation) durante três minutos à temperatura ambiente. Os cortes foram contracorados com hematoxilina de Harris, por 8 minutos e, em seguida, as lâminas foram lavadas em água corrente por 10 minutos e submetidas aos processos de desidratação e montagem em resina sintética.

Posteriormente, foi realizada a avaliação microscópica do material com o auxílio de microscópio óptico. Para a confirmação da classificação tumoral verificou-se a marcação 
positiva para cada biomarcador. No caso do anticorpo anti-uroplaquina foi considerada também a forma de marcação no urotélio, classificada como normal ou atípica. A marcação atípica foi caracterizada pela descontinuidade da marcação e presença de coloração heterogênea mais evidente na porção apical da célula, segundo descrito por Carvalho et al. (2009).

Para a avaliação da marcação da vimentina, citoqueratina e CD31 foi utilizado o teste de Quiquadrado acompanhado do teste exato de Fisher. Para avaliação da expressão da uroplaquina foi utilizado o teste de Kruskal-Wallis acompanhado do teste post hoc de Dunn. Para avaliar a correlação entre a marcação dos anticorpos foi realizado o teste de Spearman. Todos os testes foram realizados ao nível de $5 \%$ e a estatística descritiva foi utilizada para a classificação histomorfológica das lesões.

\section{Resultados e Discussão}

$\mathrm{Na}$ avaliação das 26 bexigas, 50\% (13/26) apresentaram apenas um tipo neoplásico, 26,93\% (7/26) dois tipos neoplásicos, 15,38\% (4/26) três tipos neoplásicos e $7,69 \%(2 / 26)$ quatro tipos neoplásicos.

Dentre as neoplasias encontradas, 53,85\% $(14 / 26)$ das bexigas apresentaram neoplasias de origem epitelial e $88,46 \%$ (23/26) neoplasias de origem mesenquimal. Em 38,46\% (10/26) das bexigas foram encontradas neoplasias de origem epitelial e mesenquimal, em 23,08\% (6/26) mais de um tipo de neoplasia de origem epitelial e em $15,38 \%$ (4/26) mais de um tipo de neoplasia de origem mesenquimal. As neoplasias de origem epitelial foram: carcinoma urotelial em 34,61\% (9/26); carcinoma in situ em 30,77\% (8/26) e adenocarcinoma em $15,38 \%$ (4/26) das bexigas. As neoplasias de origem mesenquimal foram: hemangioma em 50\% (13/26); mixoma em 42,31\% (11/26) e hemangiossarcoma em 7,69\% (2/26) das bexigas.
Ao avaliar os cortes submetidos à imunoistoquímica constatou-se que a citoqueratina (AE1/AE3) demonstrou expressão positiva em $100 \%$ das neoplasias de origem epitelial, assim como a expressão do biomarcador anti-vimentina foi positiva em 100\% das neoplasias de origem mesenquimal. Tanto para anti-citoqueratina quanto para anti-vimentina as células neoplásicas apresentaram marcações citoplasmáticas. As Figuras 1A e 1B ilustram a marcação com os anticorpos anticitoqueratina e anti-vimentina, respectivamente.

Houve maior frequência de marcação da citoqueratina nas neoplasias epiteliais e da vimentina em neoplasias mesenquimais mostrando diferença significativa $(p<0,05)$. Gabriel et al. (2009) também observaram em bexiga marcação positiva da citoqueratina e da vimentina em neoplasias epiteliais e mesenquimais, respectivamente.

$\mathrm{O}$ fato de ter sido encontrado no exame histopatológico das lesões observadas na bexiga de bovinos com HEB diversos tipos de processos neoplásicos de origem epitelial e mesenquimal, em um mesmo animal está de acordo com o relatado por Tokarnia, Döbereiner e Peixoto (2000) e Peixoto et al. (2003). Esta diversidade tumoral confirma o potencial carcinogênico da Pteridium aquilinum, cujos princípios tóxicos afetam tanto o urotélio quanto a lâmina própria, formados por tecidos de origem epitelial e mesenquimal, respectivamente.

Os tipos de tumores carcinoma urotelial, carcinoma in situ, adenocarcinoma, hemangioma, mixoma e hemangiossarcoma encontrados neste estudo são semelhantes aos encontrados por Carvalho, Pinto e Peleteiro (2006). Estes autores encontraram como principais neoplasias em animais com HEB tumores malignos e benignos de origem epitelial e mesenquimal, como carcinoma de células de transição (41,4\%), hemangioma (29,5\%), papiloma $(9,6 \%)$ e hemangiossarcoma (4,9\%). Hemangiomas e hemangiossarcomas também foram encontrados nos estudos realizados por Souto et al. (2006) e Gabriel et al. (2009). 
As marcações observadas no presente estudo para citoqueratina e vimentina revelaram que cada biomarcador foi específico apenas para um tipo de neoplasia, anti-citoqueratina para neoplasias epiteliais e anti-vimentina para neoplasias mesenquimais. Entretanto há casos de neoplasias em que ocorre marcação para os dois biomarcadores como no mesotelioma (PIACENTI et al., 2004) e no carcinossarcoma tireoidiano (RODRIGUES et al., 2007).

A positividade de marcação da citoqueratina em todos os carcinomas de bexiga do presente estudo estão de acordo com Lucena et al. (2011) que observaram em carcinomas renais bovinos expressão positiva para citoqueratina (AE1/AE3) em $100 \%$ dos casos avaliados.

O fato de $100 \%$ das neoplasias epiteliais terem sido marcadas pela citoqueratina (AE1/AE3), enquanto nenhuma das neoplasias mesenquimais expressou esta marcação, deve-se ao fato da citoqueratina ser um constituinte exclusivo do citoesqueleto de células epiteliais (MOLL et al., 1982). A utilização do anticorpo pancitoqueratina AE1/AE3 permite avaliar tanto a presença de citoqueratinas ácidas quanto básicas (SCHLEGEL et al., 1980), o que garantiu eficácia de 100\% nas marcações de neoplasias de origem epitelial. Trindade et al. (2004) observaram marcação positiva para a citoqueratina (AE1/AE3) em doença de Paget extramamária em que este anticorpo foi utilizado para confirmação da origem epitelial da lesão.

Por outro lado, a vimentina, por ser constituinte exclusivo do citoesqueleto de células de origem mesenquimal (IVASKA et al., 2007), não mostrou marcação em nenhuma neoplasia de origem epitelial neste estudo. Entretanto em schwannomas e neurofibromas, que são neoplasias de origem mesenquimal, esta marcação ocorreu em 100\% dos casos (VIOTT et al., 2007).

Ao avaliar o CD31 constatou-se que houve positividade em todos os vasos de todas as amostras. A marcação nas células neoplásicas ocorreu de forma significativa $(p<0,05)$ na membrana das células endoteliais tumorais nas amostras de neoplasias mesenquimais de origem vascular, como hemangiomas e hemangiossarcomas. A Figura 1C ilustra a marcação do anticorpo antiCD31 em amostras de bexiga. Albelda et al. (1991) preconizaram a utilização do CD31 ao verificarem marcação na superfície de células endoteliais, semelhante ao observado neste estudo. A positividade em $100 \%$ das neoplasias mesenquimais de origem vascular é semelhante ao descrito por Ramos-Vara (2005), comprovado por Casagrande et al. (2009) em hemangiossarcoma primário intrauterino em macaco aranha de cara vermelha e Carvalho et al. (2009) em lesões do tecido endotelial de bexigas de bovinos com HEB.

A marcação do CD31 foi negativa em 100\% das células neoplásicas dos mixomas e das neoplasias de origem epitelial, porém houve marcação dos vasos intratumorais, semelhante aos achados de Giatromanolaki et al. (1997) em carcinoma de células escamosas e adenocarcinomas pulmonares, de Yilmazer, Han e Onal (2007) em carcinoma renal de humanos e de Cristina et al. (2010) em adenomas de hipófise. Os mixomas provavelmente não expressaram marcação para o CD31, pois são constituídos de fibroblastos e tecido mucóide, que não expressam CD31. 
Figura 1. A- Fotomicrografia de bexiga bovina com hematúria enzoótica apresentando neoplasia epitelial maligna (carcinoma urotelial, P 226/10). Marcação positiva de citoqueratina (1:800) em células neoplásicas. Objetiva de 40x (barra $=20 \mu \mathrm{m}$ ). B - Fotomicrografia de bexiga bovina com hematúria enzoótica apresentando neoplasia benigna (hemangioma, P 229/10). Marcação positiva de vimentina (1:1000) em células neoplásicas. Objetiva de 20x (barra= $50 \mu \mathrm{m})$. C - Fotomicrografia de bexiga bovina com hematúria enzoótica apresentando neoplasia vascular maligna (hemangiossarcoma, P241/10). Expressão moderada de CD31 (1:200) em endotélio de vasos neoplásicos (seta) e acentuada (cabeça de seta) em endotélio de vasos não neoplásicos. Objetiva de 20x (barra $=50 \mu \mathrm{m})$. $\mathrm{D}-$ Fotomicrografia de bexiga bovina com hematúria enzoótica (P 217/10). Marcação positiva de uroplaquina (1:100) caracterizando urotélio atípico (seta). Objetiva de 40x (barra=20 $\mu \mathrm{m})$, Alegre-ES, 2012.
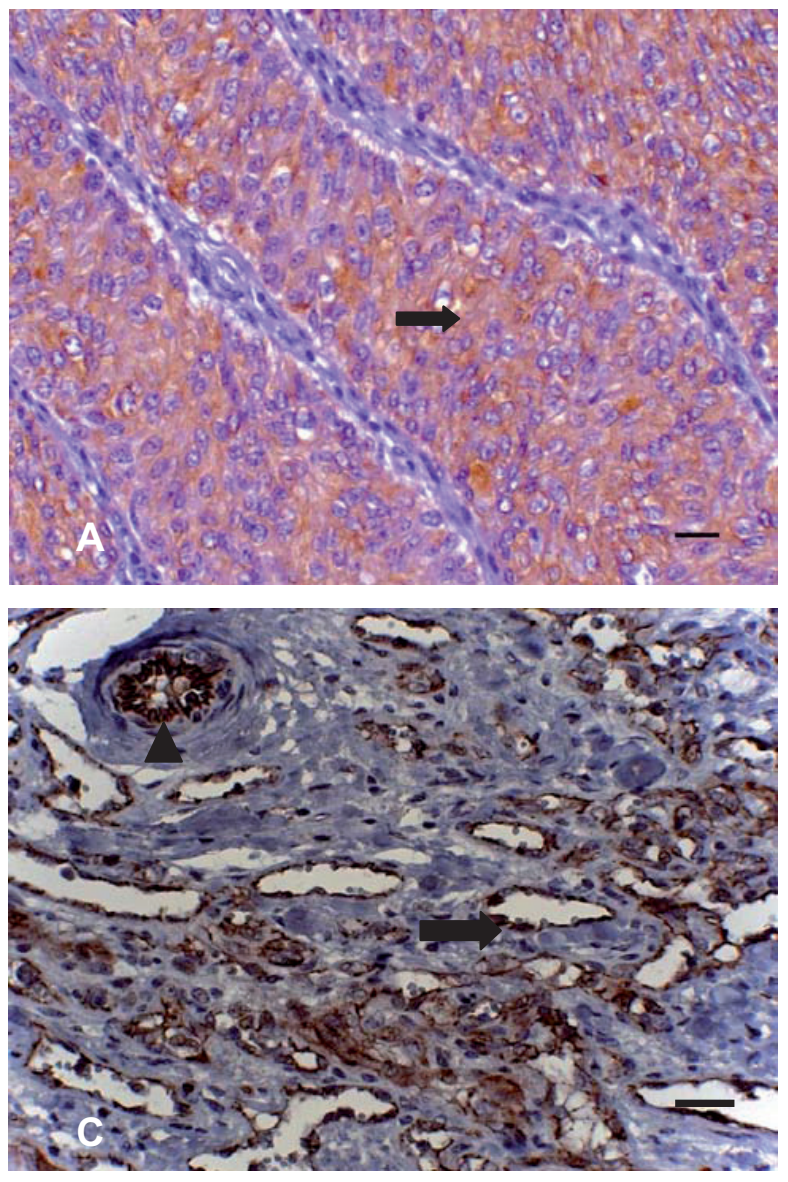

Fonte: Elaboração dos autores.

A marcação da uroplaquina III foi diferente nos diversos tipos neoplásicos e não demonstrou diferença significativa $(\mathrm{p}>0,05)$. Em relação ao tipo de marcação no urotélio, observou-se que nos carcinomas uroteliais (9/9) e nos adenocarcinomas (4/4) houve $100 \%$ de expressão atípica; nos carcinomas in situ, em 87,5\% (7/8) a marcação foi atípica e em 12,5\% (1/8) foi normal; nos hemangiomas, em 61,54\% (8/13) a marcação foi atípica, 7,69\% (1/13) normal e 30,77\% (4/13)
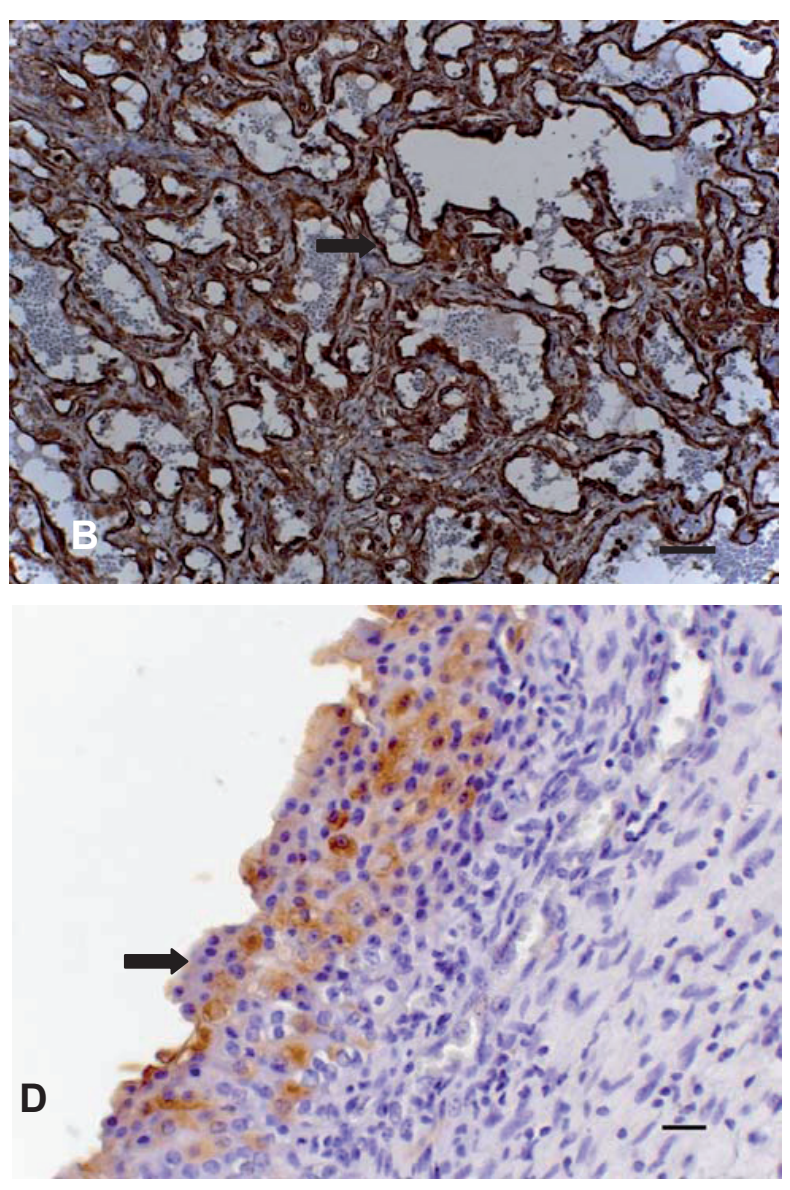

negativa; nos mixomas, 9,1\% (1/11) a marcação foi atípica, 9,1\% (1/11) normal e 81,8\% (9/11) negativa. Nos hemangiossarcomas não houve marcação do urotélio em nenhuma das amostras. A Figura 1D ilustra a marcação para o anticorpo antiuroplaquina.

Semelhante ao presente estudo, Cota (2011) observou alteração no urotélio de carcinomas de bexigas marcados com uroplaquina III nos tumores 
com alto grau de malignidade e invasivos. Carvalho et al. (2009) também verificaram urotélio adjacente às neoplasias com marcação atípica nos hemangiomas, no entanto, estes autores encontraram esta mesma marcação nos hemangiossarcomas. No presente estudo, acredita-se que não tenha sido observada marcação da uroplaquina nos hemangiossarcomas pelo caráter invasivo deste tipo de neoplasia que leva à compressão e destruição do urotélio.

A uroplaquina III é uma proteína encontrada revestindo as células mais superficiais do urotélio da bexiga e a estabilidade desta proteína frente a condições adversas serve como uma barreira eficaz para a permeabilidade celular (WU et al., 1990). As agressões à barreira que as uroplaquinas formam no urotélio permitem que princípios tóxicos cheguem aos vasos sanguíneos da submucosa e pode ocasionar hematúria e induzir edema (KYUNG; PARK; LEE, 2011). O fato de ter sido encontrada marcação atípica da uroplaquina no urotélio na maioria das neoplasias epiteliais e dos hemangiomas pode explicar a ocorrência de hematúria nos animais estudados. É possível que a marcação irregular da uroplaquina, por interferir na permeabilidade celular, possa facilitar a difusão dos princípios tóxicos da samambaia.

Por outro lado, a enorme estabilidade das uroplaquinas foi avaliada em estudos de indução de cistite em ratos pelo uso de medicamentos que demonstrou que a uroplaquina III sofreu menos danos e permaneceu mais intacta (KYUNG; PARK; LEE, 2011). Estes dados revelam que esta proteína não é facilmente danificada e isto pode indicar que os princípios tóxicos da samambaia sejam bastante nocivos às células uroteliais.

Zupancic et al. (2011) ao estudarem o comportamento da uroplaquina em urotélios normais e com lesões pré-neoplásicas de ratos constataram que mesmo em lesões pré-neoplásicas a uroplaquina III mantém sua localização. No presente estudo foi constatado presença de marcação normal da uroplaquina nos carcinomas in situ, nos hemangiomas e nos mixomas. Acredita-se que esta marcação normal tenha ocorrido em alguns casos pelo fato destes tipos neoplásicos ocuparem pequenas áreas de tecido ou por apresentarem crescimento pouco invasivo.

O fato de ter sido observada marcação negativa para uroplaquina em algumas amostras de hemangioma, mixoma e hemangiossarcoma pode ser justificada pela invasão ou destruição do urotélio adjacente. Nestas neoplasias é possível se verificar crescimento exofitico que acomete o urotélio.

Kondi-Pafiti et al. (2012) verificaram a presença de marcação da uroplaquina III em 76,66\% (23/30) dos casos de tumores ovarianos de Brenner que apresentam em sua constituição células do tipo urotelial. Trindade et al. (2004) e Torre et al. (2008) afirmam que a doença de Paget extramamária associada ao carcinoma urotelial tem marcação positiva para uroplaquina III, semelhante ao encontrado no presente estudo, em que todas as bexigas com carcinoma urotelial foram marcadas com esse biomarcador.

A análise estatística de Spearman revelou correlação positiva $\left(r_{s}=0,63, p=0,05\right)$ entre vimentina e CD31 e entre citoqueratina e uroplaquina $\left(r_{s}=0,61, p=0,05\right)$, o que indica que, na maioria das vezes em que ocorrer expressão de vimentina no tecido tumoral ocorrerá também a expressão de CD31. Assim como, quando há marcação de citoqueratina em amostra tumoral de bexiga é possível que se observe também expressão de uroplaquina.

Houve correlação negativa entre vimentina e citoqueratina $\left(r_{s}=-1, p=0,05\right)$, entre vimentina e uroplaquina $\left(r_{s}=-0,61, p=0,05\right)$, entre CD31 e citoqueratina $\left(r_{s}=-0,63, p=0,05\right)$ e entre CD31 e uroplaquina $\left(r_{s}=-0,14, p=0,05\right)$. Estes dados indicam que em neoplasias de bexiga quando há marcação de vimentina não há expressão de citoqueratina. Por outro lado, quando há expressão de vimentina a probabilidade da expressão de uroplaquina é menor. Em relação à expressão do 
CD31, quando ocorre expressão deste marcador no tecido, a expressão da uroplaquina ou citoqueratina será menor.

As correlações encontradas neste estudo estão de acordo com Ramos-Vara (2005) que citou que os tumores epiteliais como papilomas e carcinoma transicionais são positivos para marcadores biomoleculares como citoqueratina e uroplaquina III e, para os tumores de origem mesenquimal, como os vasculares, a vimentina e CD31 podem ser mais específicos. Resultados semelhantes também foram encontrados por Torres-Oliveira et al. (2001) que encontraram marcação de vimentina e CD31 e negativa para citoqueratina em neoplasias vasculares cardíacas em humanos e por PastorNavarro et al. (2010) que verificaram marcação de citoqueratina (AE1/AE3) e uroplaquina em cultivo de células uroteliais.

Concluiu-se com o presente trabalho que os animais da microrregião do Caparaó, ES acometidos pela HEB, apresentam diversos tipos neoplásicos como carcinoma urotelial, carcinoma in situ, adenocarcinoma, hemangioma, hemangiossarcoma e mixoma. Entretanto, não foi possível identificar novas variantes destes tipos neoplásicos.

A histogênese tumoral foi definida com o auxilio da imunoistoquímica e revelou que os biomarcadores anti-citoqueratina, anti-vimentina e anti-CD31 são importantes para o diagnóstico das neoplasias epiteliais, mesenquimais e vasculares, respectivamente. É possível utilizar em associação vimentina e CD31 em neoplasias mesenquimais vasculares e citoqueratina e uroplaquina em neoplasias epiteliais.

A uroplaquina demonstrou-se um marcador efetivo não somente para o diagnóstico tumoral, mas também para a avaliação da integridade urotelial.

\section{Agradecimentos}

À Fundação de Amparo à Pesquisa do Estado do Espírito Santo e à Coordenação de Aperfeiçoamento de Pessoal de Nível Superior pelo suporte financeiro.

\section{Referências}

AKIBA, J.; HARADA, H.; KAWAHARA, A.; ARAKAWA, F.; MIHASHI, H.; MIHASHI, R.; OHSHIMA, K.; YANO, H. Histiocytic sarcoma of the parotid gland region. Pathology International, Tokyo, v. 61, n. 6, p. 373-376, 2011.

ALBELDA, S. M.; MULLER, W. A.; BUCK, C. A.; NEWMANLL, P. J. Molecular and cellular properties of PECAM-1 (endoCAM/CD31): a novel vascular cell-cell adhesion molecule. The Journal of Cell Biology, New York, v. 114, n. 5, p. 1059-1068, 1991.

BEHAR, E.; CHAO, N. J.; HIRAKI, D. D.; KRISHNASWAMY, S.; BROWN, B. W.; ZEHNDER, J. L.; GRUMET, F. C. Polymorphism of adhesion molecule CD31 and its role in acute graft-versus-host disease. The New England Journal of Medicine, Massachusetts, v. 334, n. 5, p. 286-291, 1996.

BLANKENBERG, S.; BARBAUX, S.; TIRET, L. Adhesion molecules and atherosclerosis. Atherosclerosis, Amsterdam, v. 170, n. 2, p. 191-203, 2003.

BORZACCHIELLO, G.; AMBROSIO, V.; LEONARDI, L.; FRUCI, R.; GALATI, P.; ROPERTO, F. Rare tumors in domestic animals: a lipid cell variant of urothelial carcinoma of the urinary bladder in a cow and a case of vesical carcinossarcoma in a dog. Veterinary Research Communications, Dordrecht, v. 2, p. 273-274, 2004.

CAMPO, M. S.; JARRETT, W. F.; BARRON, R.; NEIL, B. W. O'.; SMITH, K. T. Association of bovine papillomavirus type 2 and bracken fern with bladder cancer in cattle. Cancer Research, Philadelphia, v. 52, n. 24, p. 6898-6904, 1992.

CARVALHO, T.; NAYDAN, D.; NUNES, T.; PINTO, C.; PELETEIRO, M. C. Immunohistochemical evaluation of vascular urinary bladder tumors from cows with enzootic hematuria. Veterinary Pathology, Madison, v. 46, n. 2, p. 211-221, 2009.

CARVAlHO, T.; PINTO, C.; PELETEIRO, M. C. Urinary bladder lesions in bovine enzootic haematuria. Journal of Comparative Pathology, Bristol, v. 134, n. 4, p. 336-346, 2006.

CASAGRANDE，R. A.; TORRES，L. N.; GOMES, M. S.; QUAGGLIA NETO, F.; KANAMURA, C.; KISHIMOTO, L.; MATUSHIMA, E. R. Hemangiossarcoma primário intrauterino em um macaco aranha de cara vermelha (Ateles paniscus). Acta Scientiae Veterinariae, Porto Alegre, v. 37, n. 1, p. 59-63, 2009.

COTA, J. B. B. Identificação de proteinas estruturais em tumores de bexiga de bovinos. 2011. Dissertação (Mestrado em Medicina Veterinária) - Universidade Técnica de Lisboa. Faculdade de Medicina Veterinária, Lisboa. 
CRISTINA, C.; PEREZ-MILLAN, M. I.; LUQUE, G.; DULCE, R. A.; SEVLEVER, G.; BERNER, S. I.; VILLALOBOS, D. B. VEGF and CD31 Association in pituitary adenomas. Endocrine Pathology, Toronto, v. 21, n. 3, p. 154-160, 2010.

ELRAYESS, M. A.; TALMUD, P. J. Platelet endothelial cell adhesion molecule-1 (PECAM-1) e coronary heart disease. Indian Journal of Medical Research, New Delhi, v. 121, n. 2, p. 77-79, 2005.

FALBO, M. K; REIS, A. C. F.; BALARIN, M. R. S.; BRACARENSE, A. P. F. R. L.; ARAÚJO JUNIOR, J. P.; OKANO, W.; SANDINI, I. E. Alterações hematológicas, bioquímicas, urinárias e histopatológicas na intoxicação natural pela samambaia Pteridium aquilinum (L.) Kühn. Semina: Ciências Agrárias, Londrina, v. 16, n. 4, p. 547558, 2005.

GABRIEL, A. L.; KOMMERS, G. D.; MASUDA, E. K.; FIGHERA, R. A.; PIAZER, J. V. M.; BARROS, C. S. L.; MARTINS, T. B.; ROSA, F. B. Aspectos clínicohematológicos e lesões vesicais na intoxicação crônica espontânea por Pteridium aquilinum em bovinos. Pesquisa Veterinária Brasileira, Seropédica, v. 29, n. 7, p. 515-525, 2009.

GIATROMANOLAKI, A.; KOUKOURAKIS, M. I.; THEODOSSIOU, D.; BARBATIS, K.; O'BYRNE, K.; HARRIS, A. L.; GATTER, K. C. Comparative evaluation of angiogenesis assessment with anti-factorVIll and anti-CD31 immunostaining in non-small cell lung cancer. Clinical Cancer Research, Philadelphia, v. 3, p. 2485-2492, 1997.

IVASKA, J.; PALLARI, H. M.; NEVO, J.; ERIKSSON, J. E. Novel functions of vimentin in cell adhesion, migration, and signaling. Experimental Cell Research, Philadelphia, v. 313, n. 10, p. 2050-2062, 2007.

KONDI-PAFITI, A.; KAIRI-VASSILATOU, E.; IAVAZZO, C.; VOUZA, E.; MAVRIGIANNAKI, P.; VLAHODIMITROPOULOS, D.; LIAPIS, A. Clinicopathological features and immunoprofile of 30 cases of Brenner ovarian tumors. Archives of Gynecology and Obstetrics, New Jersey, v. 285, n. 6, p. 1699-1702, 2012.

KYUNG, Y. S.; PARK, H. Y.; LEE, G. Preservation of uroplakins by 2-mercaptoethanesulfonate in cyclophosphamide-induced rat cystitis. Archives of Toxicology, Dortmund, v. 85, n. 1, p. 51-57, 2011.

LISTI, F.; CANDORE, G.; LIO, D.; CAVALLONE, L.; COLONNA-ROMANO, G.; CARUSO, M.; HOFFMANN, E.; CARUSO, C. Association between platelet endothelial cellular adhesion molecule 1
(PECAM-1/CD31) polymorphisms and acute myocardial infarction: a study in patients Sicily. European Journal of Immunogenetics, New Jersey, v. 31, n. 4, p. 175-178, 2004.

LUCENA, R. B.; CARMO, P. M. S.; OLIVEIRA-FILHO, J. C.; PIEREZAN, F.; TESSELE, B.; GIARETTA, P. R.; KOMMERS, G. D.; BARROS, C. S. L. Carcinoma de células renais em bovinos. Pesquisa Veterinária Brasileira, Seropédica, v. 31, n. 6, p. 487-494, 2011.

MOLL, R.; FRANKE, W. W.; SCHILLER, D. L.; GEIGER, B.; KREPELER, R. The catalog of human cytokeratins: patterns of expression in normal epithelia, tumors and cultured cell. Cell, Massachusetts, v. 31, p. 11-24, 1982.

MOSTOFI, F. K.; DAVIS, C. J. Histological typing of urinary bladder tumors. In: WORLD HEALTH ORGANIZATION (WHO). International histological classification of tumors. Springer: Berlin, 1999. p. 7-13.

OLIVEIRA, L. G. P. Novos aspectos patológicos e patogenéticos da hematúria enzoótica bovina. 2009. Dissertação (Mestrado em Ciências Clínicas e Patológicas) - Programa de Pós-Graduação em Medicina Veterinária. Universidade Federal Rural do Rio de Janeiro, Seropédica.

PASTOR-NAVARRO, T.; BEAMUD-CORTE'S, M.; FORNAS-BUIL, E.; MORATALLA-CHARCOS, L. M.; OSCA-GARCI'A, J. M.; GIL-SALOM, M. Células madre y medicina regenerativa em urología, $2 .^{a}$ parte: urotelio, vejiga, uretra y próstata. Actas Urológicas Españolas, Madri, v. 34, n. 7, p. 592-597, 2010.

PEIXOTO, P. V.; FRANÇA, T. N.; BARROS, C. S. L.; TOKARNIA, C. H. Histopathological aspects of bovine enzootic hematuria in Brazil. Pesquisa Veterinária Brasileira, Seropédica, v. 23, n. 2, p. 65-81, 2003.

PIACENTI, A. M.; OCARINO, N. M.; SILVA, A. E.; RACHID, M. A.; FRANÇA, S. A.; SERAKIDES, R. Mesotelioma pleural com metástase renal em gato. Arquivo Brasileiro de Medicina Veterinária e Zootecnia, Belo Horizonte, v. 56, n. 4, p. 558-561, 2004.

POHAR-MARINSEK, Z.; LAMOVEC, J. Angiosarcoma in FNA smears: diagnostic accuracy, morphology, immunocytochemistry and differential diagnoses. Cytopathology, Oxford, v. 21, n. 5, p. 311-319, 2010.

RADOSTITIS, O. M.; GAY, C. C.; BLOOD, D. C.; HINCHCLIFF, K. W. Veterinary medicine. A textbook of the diseases of cattle, horses, sheep, pigs and goats. 10. ed. London: Saunders, 2007. 2065 p. 
RAMOS-VARA, J. A. Imunoistoquímica, não tenha medo do marrom, vermelho e azul. In: SIMPÓSIO BRASILEIRO DA FUNDAÇÃO C. L. DAVIS, 7., 2005, Belo Horizonte. Anais... Belo Horizonte: UFMG, 2005.

RODRIGUES, A.; MASUDA, E. K.; INKELMANN, M. A.; RAMOS, A. T.; MARQUES, B. M. F. P.; MARTINS, T. B.; KOMMERS, G. D. Carcinossarcoma tireoidiano em um cão. Ciência Rural, Santa Maria, v. 37, n. 4, p. 1188-1191, 2007.

SCHLEGEL, R.; BANKS-SCHLEGEL, S.; MCLEOD, J. A.; PINKNS, G. S. Inmunoperoxidase localization of keratin in human neoplasms. The American Journal of Pathology, Philadelphia, v. 101, p. 41-50, 1980.

SILVA, M. A.; SCÁRDUA, C. M.; DÓREA, M. D.; NUNES, L. C.; MARTINS, I. V. F.; DONATELE, D. M. Prevalência de hematúria enzoótica bovina em rebanhos leiteiros na microrregião do Caparaó, Sul do Espírito Santo, entre 2007 e 2008. Ciência Rural, Santa Maria, v. 39, n. 6, p. 1847-1850, 2009.

SOUTO, M. A. M.; KOMMERS, G. D.; BARROS, C. S. L.; RECH, R. R.; PIAZER, J. V. M. Neoplasmas da bexiga associados à hematúria enzoótica bovina. Ciência Rural, Santa Maria, v. 36, n. 5, p. 1647-1650, 2006.

TOKARNIA, C. H.; DÖBEREINER, J.; PEIXOTO, P. V. Plantas tóxicas do Brasil. Rio de Janeiro: Helianthus, 2000. 310 p.

TORRE, A. C.; SUBIZAR, D.; RAMOS, M. C. G.; ENZ, P. A.; KOWALCZUK, A.; GALIMBERTI, R. ¿Eccema vulvar crónico? Revista do Hospital Italiano de Buenos Aires, Buenos Aires, v. 28, n. 2, p. 93-94, 2008.

TORRES-OLIVEIRA, F. J.; LAG-ASTURIANO, E.; TORRES-GÓMEZ, F. J.; VINUESA, P. G. G.; PÉREZDUARTE, E.; FONT-CABRERA, J. I. Angiosarcoma primario de aurícula derecha. Revista Española de Patología, Madri, v. 34, n. 1, p. 37-43, 2001.
TRINDADE, E. S.; POLCHEIRA, P. A.; BASÍLIO, D. B.; ROCHA, Z. N.; ROCHA JÚNIOR, J. L.; PEREIRA PRIMO, G. R. Doença de Paget invasiva da vulva e região perianal: relato de caso. Revista Brasileira de Ginecologia e Obstetrícia, Rio de Janeiro, v. 26, n. 4, p. 329-335, 2004.

VIOTT, A. M.; RAMOS, A. T.; INKELMANN, M. A.; KOMMERS, G. D.; GRAÇA, D. L. Aspectos histoquímicos e imunoistoquímicos nos neoplasmas do sistema nervoso periférico. Arquivo Brasileiro de Medicina Veterinária e Zootecnia, Belo Horizonte, v. 59, n. 5, p. 1145-1153, 2007.

WU, X. R.; LIN, J. H.; WALZ, T.; HANER, M.; YU, J.; AEBI, U.; SUN, T. T. A group of highly conserved urothelial differentiation-related membrane proteins. The Journal of Biological Chemistry, Rockville, v. 269, n. 18, p. 13716-13724, 1994.

WU, X. R.; MANABE, M.; YU, J.; SUN, T. T. Large scale purification and immunolocalization of bovine uroplakins I, II, and III. Molecular markers of urothelial differentiation. The Journal of Biological Chemistry, Rockville, v. 265, n. 31, p. 19170-19179, 1990.

YILMAZER, D.; HAN, U.; ONAL, B. A comparison of the vascular density of VEGF expression with microvascular density determined with CD34 and CD31 staining and conventional prognostic markers in renal cell carcinoma. International Urology and Nephrology, New Jersey, v. 39, n. 3, p. 691-698, 2007.

YU, J.; LIN, J. H.; WU, X. R.; SUN, T. T. Uroplakins Ia and Ib, two major differentiation products of bladder epithelium, belong to a family of four transmembrane domain (4TM) proteins. The Journal of Cell Biology, New York, v. 125, n. 1, p. 171-182, 1994.

ZUPANCIC, D.; ZAKRAJSEK, M.; ZHOU, G.; ROMIH, R. Expression and localization of four uroplakins in urothelial preneoplastic lesions. Histochemistry and Cell Biology, Heidelberg, v. 136, n. 4, p. 491-450, 2011. 
